\title{
A case of colitis cystica profunda in a patient with diverticulosis
}

\author{
Mike M. Bismar ${ }^{1}$, Melissa D. Gordon ${ }^{2}$ and Abdelkarim Waness ${ }^{3 *}$ \\ ${ }^{1}$ Department of Gastroenterology, Texas Health Huguley Hospital, Fort Worth, Texas - USA \\ ${ }^{2}$ Department of Pathology, Texas Health Huguley Hospital, Fort Worth, Texas - USA \\ ${ }^{3}$ Department of Medicine, New Care Center, Doha, Qatar
}

\begin{abstract}
Objective and importance: colitis cystica profunda is an unusual benign recto-colonic condition that can closely resemble the much dreaded adenocarcinoma of the colon. It is important to establish the correct diagnosis for this condition in order to prevent added investigations, worsening morbidity and higher care cost.

Clinical presentation: we present a case of colitis cystica profunda in a man known to have diverticulosis. Persistent left lower quadrant pain was his only presentation.

Intervention: The patient underwent a colonoscopy that demonstrated two sigmoid polyp-like lesions that were removed. Histopathological exam of the 2 cm polypoid lesion confirmed mucinous sub-mucosal cysts consistent with the diagnosis of colitis cystica profunda. The second polyp was a 5 mm hyperplastic polyp.

Conclusion: while benign, colitis cystica profunda can cause diagnostic and therapeutic confusion with colon cancer. Clinching the right diagnosis can prevent unnecessary further interventions and avoid additional morbidity.
\end{abstract}

\section{Introduction}

The spectrum of colonic pathologies is extremely wide. Colon cancer however remains the top priority of most preventive and therapeutic interventions. Few benign conditions can resemble its presentation: one of them is Colitis Cystica Profunda.

\section{Case presentation}

A 67 year man presented with six-week persistent left lower quadrant pain. He is known to have hypertension, hyperlipidemia and prior removal of two diminutive polyps from the sigmoid colon six years before this presentation. One was tubular adenoma and the second was hyperplastic. He was also found to have sigmoid colon diverticulosis and internal hemorrhoids. Another colonoscopy was done as part of work up for iron deficiency anemia one year later revealed only diverticulosis and internal hemorrhoids.

The patient has been taking aspirin $81 \mathrm{mg}$ daily with the rest of medications. Vital signs: Temp: 98.6F BP: 122/71 mm Hg, Pulse: 56/mn, BMI: $30 \mathrm{Kg} / \mathrm{m}^{2}$. The patient is well-nourished; his physical examination is essentially unremarkable with normal auscultation and absence of abdominal tenderness or peritoneal signs. Stool for occult blood was not done at the time. With the exception of borderline hypokalemia, his laboratory investigations, including $\mathrm{CBC}$ and metabolic profile, were within normal range. The patient was also found to have incidental 7 $\mathrm{mm}$ cholelithiasis per abdominal US and a $4 \mathrm{~mm}$ right non-obstructive nephrolithiasis per CT scan. Because of his prior colonic history of a small adenomatous polyp and the nature of his left-sided abdominal pain which was not due to diverticulitis per CT, he underwent a colonoscopy. In addition to left sided diverticulosis, two sigmoid polypoid lesions were removed: the first one was pedunculated $2 \mathrm{~cm}$ in size (Figure 1). The histopathology exam detected multiple mucin filled submucosal cysts pointing to the diagnosis of colitis cystica profunda
(Figure 2). The second polyp was only $5 \mathrm{~mm}$ in size hyperplastic in nature.

\section{Discussion}

Colitis Cystica Profunda (CCP) is a benign disease with reactive mucosal change characterized by submucosal mucin filled cysts lined by benign epithelium [1]. It is a rare colorectal condition that can closely mimic mucinous adenocarcinoma of the colon wherein lies its importance as there is no increased risk of malignancy associated with CCP. It can also manifest itself in the forms of polypoid lesions,

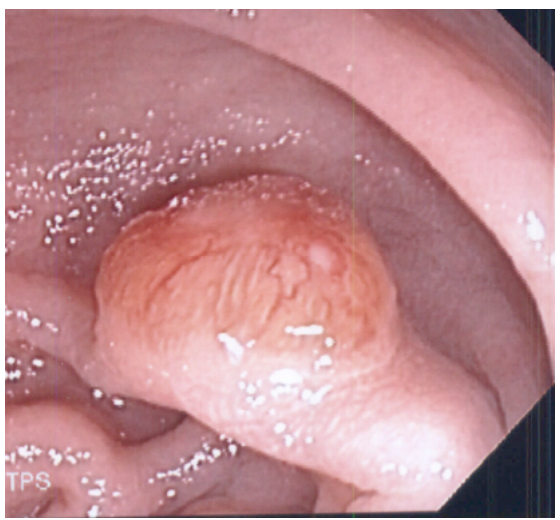

Figure 1. A $2 \mathrm{~cm}$ sigmoid polyp visualized during colonoscopy.

Correspondence to: Abdelkarim Waness, Department of Medicine, New Care Center, Doha, Qatar, E-mail: n4a1w@yahoo.com

Key words: colitis cystica profunda, diverticulosis, internal hemorrhoids

Received: April 10, 2017; Accepted: April 26, 2017; Published: April 29, 2017 


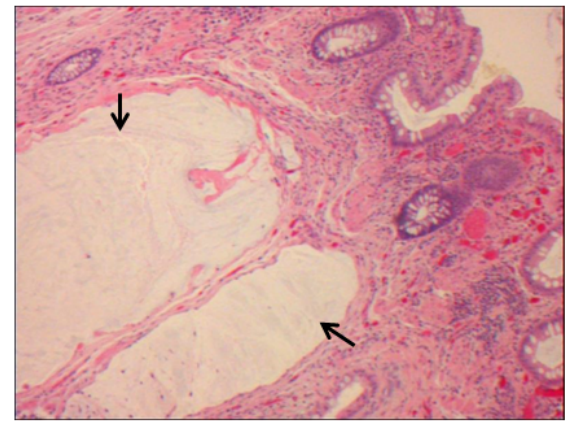

Figure 2. Submucosal mucin filled cysts (arrows) lined by bland epithelial cells(occasionally lacking associated epithelia) surrounded by a fibrous stroma.

localized sub-mucosal cysts, diffuse colonic disease or mucosal ulcerations; the latter presentation can occasionally progress into solitary rectal ulcer syndrome [2]. Colonic adenocarcinoma associated with colitis cystica profunda was also reported [3]. CCP seems to have predilection for men and seen more in the recto-sigmoid portion of the large bowel [4]. Rarely, it can result in large bowel obstruction. Clinical presentation varies from completely asymptomatic to more specific symptoms such as mild lower bowel pain, diarrhea, mucous discharge, and rectal bleeding. Rectorrhagia followed by abdominal discomfort are the two most prevalent symptoms according to a large single-center experience [5]. Other symptoms such as rectal prolapse were also described [6]. CCP can occasionally be associated with either Crohn's disease or ulcerative colitis. This association is challenging because of the inherited malignancy risk with inflammatory bowel disease $[7,8]$. CCP probably occurs due to accumulation of the mucin from the extension of the mucosal glands in the diverticuli beyond the muscularis propria as a result of a micro-perforation of the diverticulu [9]. As with our patient, he presented with left lower abdominal pain and known history of diverticulosis. Radiologic investigations such abdominal magnetic resonance imaging might assist in the diagnosis of this condition [10]. Removal of the lesion during colonoscopy and histopathology findings is the gold-standard for establishing the final diagnosis.

Colitis cystica profunda is characterized by well-formed cystic structures within the lamina propria and submucosa of the colon. The displaced mucin filled structures are lined by bland columnar (colonic type) epithelial cells containing basally located and uniform nuclei lacking significant cytologic atypia. Occasionally, there is attenuation or absence of the epithelium. Typically, there is a fibrous stroma without significant accompanying inflammation surrounding the extravasated mucin/mucinous cysts. The fibrous stroma is differentiated from a desmoplastic stroma which would be observed in adenocarcinoma. Importantly, the mucinous cysts should be smooth bordered, not infiltrative or with jagged outlines.

Establishing the correct diagnosis for colitis cystica profunda is important for at least two reasons. The first one is to truly rule-out colonic adenocarcinoma, specifically mucinous (colloid) carcinoma. This becomes tricky and critical in the remote possible association of both conditions [11]. The second reason is for the execution of appropriate therapeutic intervention(s). Because of its benign potential, CCP is usually treated endoscopically. Rare cases might require full surgical intervention [12].

Our patient did well post-colonoscopy. He is being followed regularly and is scheduled to undergo a follow-up endoscopy six months from the previous one. There are no specific guidelines for CCP monitoring beside the usual current colon care recommendations.

\section{Conclusion}

The initial findings of Colitis Cystica Profunda, such as rectal bleeding and visualization of large polyps can be worrisome and stressful for both patient and care givers. Clarifying the benign nature of CCP, by final histopathologic diagnosis, brings relief to everyone. Endoscopic removal usually takes care of this uncommon condition. More invasive surgery is rarely needed. Endoscopic monitoring for patients with this condition is advised on case by case basis.

\section{References}

1. Gonzalez R (2013) Colitis CysticaProfunda. Pathology outlines.com [2013 Aug]

2. Guest CB, Reznick RK (1989) Colitis cysticaprofunda. Review of the literature. Dis Colon Rectum 32: 983-988.[CrossRef]

3. Mitsunaga M, Izumi M, Uchiyama T, Sawabe A, Tanida E, et al. (2009) Colonic adenocarcinoma associated with colitis cysticaprofunda. Gastrointest Endosc 69:75960. [Crossref]

4. Sarzo G, Finco C, Parise P, Vecchiato M, Savastano S, et al. (2005) Colitis cysticaprofunda of the rectum: report of a case and review of the literature. ChirItal57: 789-798.[CrossRef]

5. Abid S, Khawaja A, Bhimani SA, Ahmad Z, Hamid S, et al. (2012) The clinical, endoscopic and histological spectrum of the solitary rectal ulcer syndrome: a singlecenter experience of 116 cases. BMC Gastroenterol 12: 72. [Crossref]

6. Kornprat P, Langner C, Pfeifer J, Mischinger HJ (2007) Colitis cysticaprofunda associated with rectal prolapse: report of a case. Int J Colorectal Dis 22: 1555-1556. [CrossRef]

7. Alexis J, Lubin J, Wallack M (1989) Enteritis cysticaprofunda in a patient with Crohn's disease. Arch Pathol Lab Med 113: 947-949.[CrossRef]

8. Sakurai Y, Kobayashi H, Imazu H, Hasegawa S, Matsubara T, et al. (2000)The development of an elevated lesion associated with colitis cysticaprofunda in the transverse colonic mucosa during the course of ulcerative colitis: report of a case. Surg Today 30:69-73. [Crossref]

9. Qayed E, Srinivasan S, Wehbi M (2011) A case of colitis cysticaprofunda in association with diverticulitis. Am J Gastroenterol 106: 172-173.[CrossRef]

10. Inan N, Arslan AS, Akansel G, Anik Y, Gürbüz Y, et al. (2007) Colitis cysticaprofunda: MRI appearance. Abdom Imaging 32: 239-242.[CrossRef]

11. Lord A, Hompes R, Arnold S, Venkatasubramaniam A (2015) Ultra-low anterior resection with coloanal anastomosis for recurrent rectal prolapse in a young woman with colitis cysticaprofunda. Ann R Coll Surg Engl 97: e32-3. [Crossref]

12. Friedman E, Tueller EE (1975) Colitis cysticaprofunda: colonoscopic and pathological findings. Gastrointest Endosc 22: 40-41.[CrossRef]

Copyright: (C2017 Bismar MM. This is an open-access article distributed under the terms of the Creative Commons Attribution License, which permits unrestricted use, distribution, and reproduction in any medium, provided the original author and source are credited. 